\title{
Tecnologia social e desenvolvimento local: reflexões a partir da análise do Programa Um Milhão de Cisternas
}

Rafael de Brito Dias

Programa de Pós-Graduação em Política Científica e Tecnológica da Universidade Estadual de Campinas (UNICAMP)

Recebido: 13/02/2013 Versão revisada (entregue): 29/11/2013 Aprovado: 03/12/2013

\begin{abstract}
Resumo
O Programa Um Milhão de Cisternas (P1MC) é considerado um dos casos de desenvolvimento de tecnologias sociais mais exitosos no Brasil, levando benefícios significativos para a população do Semiárido Brasileiro (SAB) desde sua criação, em 2003. A complexidade sociotécnica que encerra um programa como esse demanda a utilização de um referencial analítico adequado, não apenas à compreensão da tecnologia em si, mas das condições sociais e técnicas do entorno. $\mathrm{O}$ sucesso do $\mathrm{P} 1 \mathrm{MC}$, em comparação com outras iniciativas orientadas para a garantia do acesso à água no $\mathrm{SAB}$, reside, sobretudo, na mudança da forma como o problema a ser atacado foi construído: a tradicional abordagem de políticas orientadas para o combate à seca passa a ser substituída por uma perspectiva de convivência com a seca. A posição central nesse processo é ocupada pela cisterna, "tecnologia social" que, para além do acesso à água, tem garantido a inclusão social, o empoderamento de atores politicamente marginalizados e a construção de laços de solidariedade e de cooperação nas comunidades. Este artigo examina essa experiência, procurando apontar para a possibilidade - e a necessidade - de um diálogo sistemático entre a tecnologia social e o desenvolvimento local.
\end{abstract}

Palavras-chave | Cisternas; desenvolvimento local; políticas públicas; Semiárido Brasileiro; tecnologia social.

Código JEL | O29; O38; Q25.

\section{SOCIAL TECHNOLOGY AND LOCAL DEVELOPMENT: REFLECTIONS SINCE THE ANALYSIS OF THE ONE MILLION CISTERNS PROGRAM}

\begin{abstract}
The One Million Cisterns Program (P1MC) is considered one of the most successful cases of development of social technologies in Brazil, bringing significant benefits to the population of the Brazilian Semi-Arid (SAB) since its creation in 2003. The socio-technical complexity that corresponds to a program like this requires the use of an appropriated analytical framework, not only for the understanding of the technology itself, but of the social and technical conditions of the surroundings. The success of P1MC compared to other measures to ensure access to water
\end{abstract}


in $\mathrm{SAB}$ lies, primarily, in changing the way the problem to be faced was built: the traditional approach of policies directed to combat drought starts to be replaced by an approach of dealing with drought. The central position in this process is occupied by the cistern, a "social technology" that, in addition to the access of water, has ensured social inclusion, the empowerment of politically marginalized actors and building links of solidarity and cooperation in communities. This article examines this experience, trying to point out the possibility - and necessity - of a systematic dialogue between social technology and local development.

Keywords | Brazilian Semi-Arid; Cisterns; local development; public policies; social technology.

JEL-Code | O29; O38; Q25.

\section{LA TECNOLOGÍA SOCIAL Y EL DESARROLLO LOCAL: REFLEXIONES A PARTIR DEL ANÁLISIS DEL PROGRAMA UN MILLÓN DE CISTERNAS}

\section{Resumen}

El Programa Un Millón de Cisternas (P1MC) es considerado uno de los casos de desarrollo de tecnologías sociales más exitosos en Brasil, aportando importantes beneficios para la población del Semiárido Brasileño (SAB) desde su creación en 2003. La complejidad socio-técnica que corresponde a un programa de este tipo requiere el uso de un marco analítico adecuado, no solo para la comprensión de la tecnología en sí, sino también de las condiciones sociales y técnicas de su entorno. El éxito del P1MC en comparación con otras iniciativas orientadas para garantizar el acceso al agua en el SAB se encuentra principalmente en el cambio de la forma como el problema fue construido: el tradicional enfoque de políticas dirigidas a combatir la sequía pasa a ser substituido por una perspectiva de convivencia con la sequía. La posición central en este proceso es ocupada por la cisterna, "tecnología social" que, además del acceso al agua, ha asegurado la inclusión social, el empoderamiento de actores políticamente marginados y la construcción de lazos de solidaridad y cooperación en las comunidades. En este artículo se examina el P1MC, buscando apuntar a la posibilidad - y a la necesidad - de un diálogo sistemático entre la tecnología social y el desarrollo local.

Palabras-clave | Cisternas; desarrollo local; políticas públicas; Semiárido Brasileño; tecnología social.

Código JEL | O29; O38; Q25.

\section{Introdução}

Recentemente, as reflexões acerca das tecnologias para a intervenção sobre problemas de caráter social têm recuperado fôlego. As "tecnologias apropriadas", as "tecnologias para a inclusão social" e as "tecnologias sociais" - os termos que têm se popularizado no Brasil durante a última década - representam alternativas tecnológicas interessantes, que têm provado ser importantes ferramentas para a promoção da inclusão social e o fortalecimento das práticas democráticas e, também, no âmbito das estratégias de desenvolvimento sustentável no longo prazo. 
São essas as tecnologias para as quais direcionamos as reflexões apresentadas neste artigo, no qual buscamos apresentar a Tecnologia Social (ou "TS") como movimento no âmbito do qual tem sido geradas reflexões e experiências aderentes às concepções sobre desenvolvimento local que, paralelamente, vêm sendo geradas no Brasil e no exterior. Com a finalidade de apresentar as potenciais contribuições da Tecnologia Social para o tema, partimos de uma breve discussão conceitual, de caráter mais geral, para posteriormente apresentar uma análise de base empírica, fundamentada no caso de uma das mais interessantes experiências de desenvolvimento de tecnologias sociais no Brasil: o Programa Um Milhão de Cisternas (P1MC).

O P1MC é considerado um dos casos de desenvolvimento de tecnologias sociais mais exitosos no Brasil. Desde a instituição do Programa, em 2003, foram construídas mais de 400 mil cisternas de placas pré-moldadas na região do Semiárido Brasileiro (SAB), beneficiando quase dois milhões de pessoas. O SAB engloba uma área de aproximadamente $975 \mathrm{mil} \mathrm{km}^{2}$, que abriga cerca de 25 milhões de pessoas. Na região, a precipitação média anual varia entre $200 \mathrm{~mm}$. e $1.000 \mathrm{~mm}$., e a distribuição da chuva é altamente irregular. Além disso, o subsolo da região é pobre em água (ou, quando está presente, esta é salobra e imprópria para o consumo).

Esse quadro peculiar conforma uma situação precária que afeta diretamente milhões de pessoas. A complexidade sociotécnica que encerra um programa como esse demanda a utilização de um referencial analítico adequado não apenas à compreensão da tecnologia em si, mas das condições sociais e técnicas do entorno. Os problemas (e aqueles relacionados à escassez da água não são exceções) desafiam a usual distinção entre "técnico" e "social": eles são, de fato, sociotécnicos.

Também as soluções empregadas para combatê-los devem ser entendidas como resultantes de processos sociotécnicos complexos. A análise que empregamos nesta pesquisa busca integrar categorias e conceitos utilizados nos enfoques disciplinares que compõem o campo dos Estudos Sociais da Ciência e da Tecnologia (em particular, da Sociologia da Tecnologia), da Economia Solidária e das reflexões acerca da tecnologia apropriada e da tecnologia social. Com base nessa perspectiva interdisciplinar é possível dar conta de toda a complexidade que envolve esses processos.

As conclusões preliminares apontam para o fato de que o "sucesso" do programa (e, por extensão, da tecnologia) deveu-se à força das alianças sociotécnicas que se conformaram ao seu redor, potencializando seu funcionamento. Uma tecnologia relativamente fluida, o interessamento de atores governamentais e a construção de um discurso de "convivência com a seca" (e não de "enfrentamento da seca") foram elementos fundamentais no sentido de garantir o sucesso do P1MC e da tecnologia das cisternas de placas pré-moldadas a ele atrelada. Espera-se que a 
análise apresentada neste artigo possa servir de insumo para outras reflexões acerca da temática das tecnologias para a inclusão social, bem como para políticas públicas orientadas a elas.

\section{O que é Tecnologia Social?}

O conceito de Tecnologia Social tem se difundido rapidamente no Brasil (e, mais recentemente, na América Latina), ao longo dos últimos anos. Pretendemos, aqui, expor alguns elementos que permitam que o leitor familiarizado com a discussão sobre desenvolvimento local, mas não com aquela a respeito da Tecnologia Social, possa melhor compreender de que ponto partimos em nossa argumentação. Para tanto, apresentamos aqui algumas das definições (ou aproximações conceituais) mais comumente empregadas a respeito da TS.

A Rede de Tecnologia Social (RTS), principal instância de articulação de experiências e reflexões sobre TS no Brasil, define seu objeto como um conjunto de "produtos, técnicas e/ou metodologias reaplicáveis, desenvolvidas na interação com a comunidade e que represente efetivas soluções de transformação social". Trata-se de uma definição ampla, que possibilitou a adesão de um grande número de instituições (ONGs, movimentos sociais, prefeituras, universidades, empresas etc.) à Rede.

Entretanto, a despeito dessa "vantagem política", a amplitude do conceito empregado pela RTS traz também uma desvantagem: quando se trata de pensar em possibilidades de políticas públicas, a ausência de foco pode comprometer o resultado potencial da intervenção estatal. Tratando-se de uma área em que os recursos já são escassos, a pulverização pode comprometer a eficácia das políticas. Nesse caso, por exemplo, nota-se que muitas das metodologias às quais a Rede se refere com frequência não envolvem elementos que permitam que sejam efetivamente entendidas como tecnologias.

Uma forma alternativa de compreender a Tecnologia Social é bastante intuitiva: ela seria o oposto da tecnologia convencional, cotidianamente empregada nas esferas de produção, circulação e consumo de mercadorias nas sociedades contemporâneas. De um modo geral, a tecnologia convencional pode ser definida a partir de um conjunto de características (relativas a seus efeitos sobre o trabalho, à sua escala de produção ótima, aos seus efeitos sobre o meio ambiente, às características dos insumos utilizados na produção, ao ritmo da produção, ao tipo de controle exercido sobre os trabalhadores, etc.) que a distingue da tecnologia social.

Conforme mostra Dagnino (2004), a tecnologia convencional (TC) é inerentemente poupadora de mão de obra (o que pode ser verificado na constante substituição do trabalho humano por trabalho mecânico). A tecnologia 
convencional é segmentada, não permitindo que o produtor direto exerça controle sobre a produção; é alienante, pois suprime a criatividade do produtor direto; é hierarquizada, pois exige que haja a posse privada dos meios de produção e o controle sobre o trabalho; tem como objetivo principal (senão único) maximizar a produtividade, ainda que isso tenha efeitos negativos sobre o nível de emprego; a TC é, ainda, irradiada pelas empresas dos países desenvolvidos e simplesmente absorvida de forma acrítica pelas empresas dos países subdesenvolvidos; por fim, a TC impõe aos países desenvolvidos padrões que são orientados pelos mercados dos países desenvolvidos, de alta renda.

Assim, frente às considerações apresentadas acima, é plausível afirmar que a tecnologia capitalista convencional reforça a dualidade capitalista, submetendo trabalhadores a detentores dos meios de produção e países subdesenvolvidos a países desenvolvidos, perpetuando e ampliando as assimetrias de poder dentro das relações sociais e políticas. Nesse sentido, a TC pode ser vista como um elemento que provoca a gradual erosão da democracia e potencializa as dinâmicas de exclusão econômica e social que afligem as sociedades contemporâneas.

Para Dagnino (2004), a tecnologia convencional teria como principais características:

1) É segmentada: não permite controle do produtor direto;

2) É alienante: não utiliza potencial do produtor direto;

3) É hierarquizada: demanda a figura do proprietário, do chefe etc.;

4) Maximiza a produtividade em relação à mão de obra ocupada;

5) Possui padrões orientados pelo mercado externo de alta renda e para grandes empresas dos países ricos.

A Tecnologia Social, em contraposição, reuniria características como:

1) adaptada a pequenos produtores e consumidores de baixo poder econômico;

2) não promovedora do controle, segmentação, hierarquização e dominação nas relações patrão-empregado;

3) orientada para o mercado interno de massa;

4) incentivadora do potencial e da criatividade do produtor direto e dos usuários;

5) capaz de viabilizar economicamente empreendimentos como cooperativas populares, incubadoras e pequenas empresas.

Ainda segundo Dagnino (2004), a Tecnologia Social deveria ter como base os empreendimentos autogestionários e as micro e pequenas empresas. Assim, a TS deveria ser adaptada à pequena escala, tanto no sentido físico quanto financeiro, o que favoreceria os trabalhadores e pequenos proprietários em geral, além de não criar uma discriminação entre patrões e empregados e permitir a plena utilização do potencial criativo do produtor direto. Por fim, a tecnologia social estaria mais 
imbricada à realidade das sociedades locais, de modo que pudesse gerar respostas mais adequadas aos problemas colocados em um determinado contexto. No caso do Brasil, por exemplo, isso se traduziria em um deslocamento do foco de destino da produção, do mercado externo, de alta renda, para o mercado interno, de massa.

Dessa forma, observa-se que, enquanto a tecnologia capitalista convencional é funcional para a grande empresa privada (em especial para as grandes empresas multinacionais) e para uma pequena elite para quem a promessa do acesso à totalidade de bens e serviços produzidos no capitalismo contemporâneo efetivamente se realiza, a Tecnologia Social favoreceria, principalmente, aos trabalhadores cooperados e aos pequenos produtores.

Uma terceira forma de compreender a Tecnologia Social envolve um retorno às ideias do movimento da Tecnologia Apropriada (TA), cujas bases remetem, de acordo com Dagnino; Brandão; Novaes (2004), à Índia do final do século XIX. A TA surge, nesse momento, como uma forma de resistência à dominação britânica. Embora não fosse a primeira tentativa de resistência através da tecnologia - não poderíamos desprezar, por exemplo, a importância do ludismo - a TA representou, certamente, a iniciativa mais ampla e duradoura dessa natureza.

Como forma de resistência ao imperialismo britânico, a Tecnologia Apropriada foi, como era de se esperar, abraçada com certo entusiasmo por Gandhi, na segunda metade da década de 1920. A partir de programas idealizados pelo Mahatma, surgiram ou foram recuperados os primeiros artefatos a serem amplamente reconhecidos como tecnologias apropriadas como, por exemplo, a charkha, uma espécie de roca de fiar (DAGNINO; BRANDÃO; NOVAES, 2004).

Nada mais natural, aliás, que a via de resistência tecnológica encontrada pelos indianos tenha apontado para a confecção de têxteis, atividade que foi responsável pela centelha da Revolução Industrial e na qual o capital britânico tinha, naturalmente, muito interesse.

À medida que as iniciativas indianas ao redor da Tecnologia Apropriada foram se desenvolvendo, foi se tornando mais claro que aquele estilo alternativo de tecnologia não representava apenas um instrumento de resistência à dominação britânica. Era, também, um poderoso elemento transformador da ordem social.

A organização do trabalho dentro das fábricas e a apropriação privada do excedente, dentre uma série de outros aspectos, representam características próprias da tecnologia convencional. E, além disso, constituem elementos que reforçam estruturas e relações particulares. Dessa forma, a adoção de um estilo tecnológico alternativo permite também a subversão de certos arranjos sociais convencionais.

A adoção da charkha, por exemplo, modificou, em alguma medida, o espaço no qual ocorria a produção de têxteis. Das fábricas de grande porte localizadas em 
cidades maiores, parte da confecção foi deslocada para modestos arranjos produtivos presentes nas pequenas vilas espalhadas pelo subcontinente indiano. Isso permitiu uma aproximação da atividade produtiva em relação às comunidades locais, tornando tênue (e até mesmo supérflua) a fronteira entre produtores e usuários. De certa forma, essa mudança ilustra uma das expressões mais emblemáticas do movimento de resistência na Índia da primeira metade do século XX: "produção pelas massas, não produção em massa". Além disso, a opção pela charkha, assim como por outras tecnologias apropriadas, permitiu o desenvolvimento de saberes tradicionais, o que provavelmente seria comprometido caso tivesse ocorrido a manutenção da tecnologia convencional. A consequência desse processo foi o empoderamento das comunidades locais, o que levou a uma pressão (ainda que insuficiente para causar uma ruptura) sobre a própria estrutura social indiana.

De acordo com Dagnino; Brandão; Novaes (2004), o movimento da Tecnologia Apropriada disseminou-se para além da Índia, tendo chegado, por exemplo, à China maoísta, onde também encontrou terreno fértil para seu desenvolvimento. Sua chegada ao ocidente, contudo, ocorreu com significativo atraso (apenas na década de 1970) e pelo caminho das ideias, não da prática. Essas reflexões obtiveram visibilidade no mundo ocidental a partir do trabalho de Schumacher (1999).

O movimento da Tecnologia Apropriada representa, sob muitos aspectos, a matriz a partir da qual originou-se, algumas décadas depois, o da Tecnologia Social. O movimento pela TS não representa, evidentemente, uma derivação acrítica daquele da TA, mas uma reformulação de suas bases, a partir das críticas às quais foi submetido, seus sucessos e seus fracassos.

A necessidade de sofisticar e complementar o conceito de Tecnologia Social, possibilitando seu emprego enquanto orientador de reflexões e estratégias de intervenção, ainda está pendente. Nesse sentido, partindo dos elementos acima expostos e reconhecendo as potencialidades e os limites das definições apresentadas, sugerimos pensar na Tecnologia Social como a base material e cognitiva de uma sociedade mais justa, solidária, democrática e ambientalmente sustentável, em consonância com os principios da autogestão, do cooperativismo e do desenvolvimento local.

Nesse sentido, aproximamo-nos de autores como Clarke (1972) e Varsavsky (1976). Ao apontar para a necessidade de uma tecnologia que fosse orientada por "metas técnicas válidas "para todos os homens, em todos os tempos", Clarke defendia um estilo tecnológico que transcendesse os elementos sobre os quais a construção da tecnologia esteve convencionalmente apoiada. Uma constatação importante é a de que, embora a argumentação do autor deixe suficientemente claro que sua visão da tecnologia não é a-histórica ou apolítica, sua proposta é a de um estilo tecnológico pautado por valores supostamente universais. Essa aparente contradição não compromete propriamente a forte carga normativa que pauta as 
ideias do autor, mas são, sem dúvida alguma, uma amostra de sua afeição pelo utópico, com a qual compartilham muitos dos envolvidos com o movimento da Tecnologia Social.

Varsavsky, por sua vez, defendia a construção do "socialismo nacional criativo": uma sociedade caracterizada pela solidariedade (e não pela competição), pela participação popular na tomada de decisões, pela distribuição igualitária do acesso a bens e serviços, por padrões de consumo mais modestos, pela supressão do imperialismo e da dependência econômica e tecnológica, pelo desenvolvimento da cultura nacional, pela educação como meio de permitir a formação de cidadãos novos, solidários, participantes e criativos. Compreendamos, pois, a Tecnologia Social como o caminho a seguir de modo a realizar esse objetivo, e não como o objeto ou produto em si. É sobre essa interpretação que a análise que segue está fundamentada.

\section{O Programa Um Milhão de Cisternas (P1MC)}

A água é, evidentemente, um recurso fundamental à vida humana. Sua importância excede as dimensões do consumo humano e do uso doméstico: a água é usada em atividades tão diversas quanto a agricultura (para irrigação), a pecuária (para consumo animal), a indústria e os serviços. É, portanto, fundamental não apenas à dimensão biológica da vida humana, mas também à social. A abundância ou escassez de água, por exemplo, pode ser um fator determinante dos hábitos de consumo de uma determinada comunidade.

Os problemas associados à escassez da água (ou a sua impropriedade para consumo) são numerosos e diversos. No Brasil, estes são mais comuns no Semiárido, onde os problemas relacionados à seca são notáveis. Como já visto na introdução, o Semiárido Brasileiro (SAB), com aproximadamente 975 mil km² (sendo, portanto, maior que a Venezuela) e abrigando cerca de 25 milhões de pessoas (duas vezes a população da Bolívia) é uma região de porte expressivo. Nela, a precipitação média anual varia entre $200 \mathrm{~mm}$. e $1.000 \mathrm{~mm}$. e a distribuição da chuva é altamente irregular. Além disso, o subsolo da região é pobre em água (ou, quando está presente, esta é salobra e imprópria para o consumo) (GNADLINGER, 2001). Esse quadro bastante peculiar conforma uma situação precária que afeta diretamente milhões de pessoas.

O desenvolvimento de culturas agrícolas no Semiárido é uma questão de natureza altamente complexa. Um mapeamento realizado pela EMBRAPA, em 2002, apontou que $36 \%$ do $\mathrm{SAB}$ correspondem a áreas de reservas ecológicas que não são apropriadas para a agricultura; 40\% são apropriados para o uso agropecuário limitado (criação de caprinos e ovinos); 16\% permitem agricultura com uso da 
água de chuva; e a agricultura irrigada é viável em menos de $4 \%$ do total das terras do Semiárido Brasileiro (GUIMARÃES FILHO; LOPES, 2002).

Os dados apresentados por Lipps (2007) nos permitem dimensionar o tamanho desses problemas no mundo. Atualmente, mais de um bilhão de pessoas não têm acesso à água potável, enquanto quase dois bilhões não têm acesso a saneamento básico. Uma em cada cinco crianças não tem acesso à água em condições para consumo; diariamente, cerca de 3,9 mil crianças morrem em decorrência de problemas associados à falta de água ou de saneamento nas comunidades onde vivem. Doenças transmitidas pela água causam, anualmente, mais de dois milhões de mortes.

A complexidade sociotécnica associada a experiências de produção de tecnologias orientadas para a intervenção sobre problemas dessa natureza demanda a utilização de um referencial analítico adequado não apenas à compreensão da tecnologia em si, mas das condições sociais e técnicas do entorno. Os problemas (e aqueles relacionados à escassez da água não são exceções) desafiam a usual distinção entre "técnico" e "social": eles são, de fato, sociotécnicos. Também as soluções empregadas para combatê-los devem ser entendidas como resultantes de processos sociotécnicos complexos.

O problema da seca no $\mathrm{SAB}$ tem sido debatido há décadas. Inúmeras ações já foram discutidas e algumas implementadas, mas sem solução definitiva para os problemas que assolam os moradores da região.

O Programa Um Milhão de Cisternas tem apresentado interessantes resultados desde sua implementação, e certamente constitui uma experiência digna de estudo e reflexão. Ele tem sido considerado um dos casos de desenvolvimento de tecnologias sociais mais exitosos no Brasil. Desde sua instituição, em 2003, foram construídas mais de 520 mil cisternas, número que segue crescendo rapidamente em direção à meta de um milhão ${ }^{1}$. Com isso, estima-se que o número de pessoas hoje beneficiadas pelo Programa seja próximo a dois milhões.

O P1MC representa um esforço de reunir, sob um programa federal unificado, os esforços difusos de construção de cisternas no SAB a partir do início da década de 2000. Tais ações têm sido marcadas sobremaneira pela atuação da Articulação do Semiárido (ASA), uma rede de organizações cujo objetivo é viabilizar iniciativas que permitam aos habitantes do $\mathrm{SAB}$ conviver com a seca.

O que a ASA conseguiu, assim, foi reconstruir um problema antigo (a questão da seca no $\mathrm{SAB}$ ), a partir de uma nova perspectiva e, ao fazê-lo, reordenar as alianças necessárias para garantir o funcionamento do modelo de política pública então em

1 A evolução dessa cifra pode ser acompanhada no site do Ministério do Desenvolvimento Social, em que está disponível um "contador de cisternas" para consulta: http://www.mds.gov.br/segurancaalimentar/acessoaagua/cisternas. 
gestação em consonância com seu projeto e com as necessidades da população do Semiárido.

Nota-se aí um dos diferenciais que explica o sucesso da ASA nas ações que tem formulado e implementado. Por décadas, têm sido em vão as tentativas de "superar" ou "conviver" com a seca. Tais iniciativas não solucionaram os problemas aos quais a população local esteve submetida. Muitos não encontraram outra saída senão abandonar a terra onde viviam e migrar em direção aos grandes centros urbanos, onde frequentemente se deparavam com uma situação de pobreza e de exclusão não muito distinta daquela da qual pretendiam fugir.

A filosofia de convivência com a seca difundida pela ASA tem se mostrado uma alternativa interessante nesse sentido, ao propor ações que possibilitem uma vida digna para a população local, sem que tenha que abandonar o local onde vive. Isso implica, evidentemente, a necessidade de pensar soluções para os problemas gerados pela seca. E envolve, claro, o desenvolvimento e a reaplicação de tecnologias concebidas especificamente para esse fim.

A cisterna é o motor do P1MC. Trata-se de uma tecnologia simples e de fácil reaplicação, sendo estas algumas das características que explicam sua rápida disseminação pelo SAB. A cisterna padrão é uma construção circular com raio de cerca de 2 metros construída sobre um buraco de 1,2 metros de profundidade (podendo variar em função do terreno), com capacidade para armazenar até 16 mil litros de água.

A cisterna é construída nas proximidades da moradia, sendo conectada ao telhado da casa por uma calha. A água coletada na primeira chuva da estação lava todo o sistema e deve ser descartada. A partir daí a água das chuvas seguintes é coletada e armazenada na cisterna, sendo consumida durante os meses de estiagem ${ }^{2}$.

O custo médio para a construção de uma cisterna é de aproximadamente $R$ \$ 1,8 mil, um investimento bastante razoável, considerados os benefícios proporcionados pela cisterna. Os recursos, provenientes do MDS, são liberados para as prefeituras municipais por meio de editais.

De acordo com o Ministério do Desenvolvimento Social, uma única cisterna com capacidade para 16 mil litros de água pode suprir as necessidades de consumo de uma família de até cinco pessoas por oito meses, correspondentes ao período de estiagem no SAB. O consumo parcimonioso da água é um aspecto fundamental para o sucesso desse programa, e tem sido alcançado por meio de ações de conscientização promovidas pela ASA, na direção das "ações complementares" descritas anteriormente neste artigo.

\footnotetext{
${ }^{2}$ Especificações técnicas e um "passo a passo" detalhado para a construção das cisternas estão disponíveis no manual do MDS em: http://www.mds.gov.br/segurancaalimentar/acessoaagua/ cisternas.
} 
Outro aspecto interessante do Programa é o envolvimento das famílias na construção das cisternas, geralmente construídas por mutirões. Uma pessoa que tenha alguma experiência como pedreiro participa de oficinas de qualificação promovidas pela ASA e, ajudado por familiares, amigos ou vizinhos, consegue construir a cisterna em alguns dias de trabalho. Respeita-se, assim, o conhecimento tradicional - e, muitas vezes, tácito - detido pelos próprios usuários.

Os resultados positivos da construção das cisternas são muitos. Os beneficiários frequentemente apontam, por exemplo, para a economia de tempo proporcionada pela disponibilidade de água nas cisternas - o que evita que tenham que buscar água em outros locais. Isso permite a intensificação de outras atividades, como o roçado, o manejo dos animais e os trabalhos domésticos. A tarefa de buscar água, que geralmente recai sobre mulheres e crianças, é eliminada. Famílias se emancipam e podem conviver com a seca em condições dignas.

O que explica, enfim, o sucesso do P1MC? Por um lado, são as próprias características da tecnologia. É barata, é simples, é adequada à pequena escala e pode ser facilmente reaplicada. É um sistema eficiente que garante água, saúde e dignidade para as pessoas que moram no SAB. Não elimina os conhecimentos tradicionais (pelo contrário, serve-se deles). É construída com materiais disponíveis nas próprias localidades e não tem efeito nocivo sobre o meio ambiente. É, enfim, a materialização de todas as características que se esperaria encontrar em uma tecnologia social "bem sucedida".

Mas não são apenas esses fatores que explicariam o sucesso do Programa. Ele tem sido bem sucedido também por envolver uma nova perspectiva acerca do problema da seca. A ideia de convivência, nesse caso, mostra-se bem mais interessante que a noção de "combate" ou de "superação".

De fundamental importância foi também a geração de interesse por parte da ASA, suficiente para estabelecer uma rede sociotécnica longa envolvendo o MDS. Com o apoio do Ministério, as ações pontuais puderam ser reaplicadas em escala, dando ao Programa uma dimensão significativa. Tais fatores explicam, em conjunto, o sucesso do P1MC.

É interessante notar, contudo, que o sucesso do Programa tem gerado interesse de outros atores com motivações bastante distintas daqueles diretamente envolvidos com as cisternas (famílias, prefeituras locais, MDS, ASA). No início de 2012, o Governo Federal optou por comprar cisternas de plástico, em substituição aos modelos tradicionais empregadas no âmbito do P1MC (notadamente o modelo de "cisternas de placas pré-moldadas").

Essa decisão subverte um aspecto importante do Programa, ainda que não facilmente reconhecível: o processo de desmercantilização da água possibilitado pela construção das cisternas. Desenhos tradicionais de políticas públicas orientadas à garantia do acesso à água, em geral, partem do princípio de que, por 
ser a água um recurso escasso e de uso excludente, é preciso cobrar por seu consumo (Dinar, 2000). Mas faria pouco sentido fazê-lo em uma região onde a tarifação, por menor que fosse, teria impacto significativo sobre o orçamento de muitas das famílias. O reconhecimento da água como um bem gratuito, ainda que não fosse um aspecto inicialmente planejado do Programa, acabou por tornar-se, justamente, um dos fatores que favoreceram seu funcionamento.

Em meio a essa mudança, claramente impulsionada por interesses econômicos privados, a luta pela dignidade, pela inclusão, pela superação da pobreza - objetos da tecnologia social - passa a ser vista como oportunidade de negócio pelas grandes empresas. Há aí um risco de subversão dos valores de cooperação, solidariedade e desmercantilização que se apresentam de forma tão interessante nesse caso. A ironia reside no fato de que o assédio de determinados atores foi, justamente, despertado pelo histórico de sucesso e pelo grande reconhecimento que o P1MC tem conquistado.

A lição, neste caso, é bem clara: é difícil produzir inovações significativas em políticas públicas, sobretudo quando contemplam tecnologias sociais. A racionalidade dos atores envolvidos com a formulação de políticas é fortemente marcada pela ideia de que a figura do mercado é imprescindível para produzir dinâmicas de inclusão social e de desenvolvimento local. Pensar em alternativas de intervenção estatal fora do mercado, ainda que um desafio para um Estado capitalista, seria um passo fundamental para alavancar iniciativas como a discutida neste artigo. É preciso, pois, repensar o modelo de política pública sobre o qual estariam pautadas as ações de promoção de tecnologias sociais.

\section{Políticas públicas e desenvolvimento local: a necessidade de novas abordagens}

Um dos jargões frequentemente repetido por aqueles que tratam da relação entre desenvolvimento local e políticas públicas é "pensar globalmente, agir localmente". Trata-se de um daqueles casos em que a repetição excessiva acabou por esvaziar a expressão de significado.

O agir local, em especial, constitui um dos maiores desafios em termos de políticas públicas, sobretudo em um contexto em que, em decorrência do processo de reforma do Estado conduzida no Brasil, criou-se uma espécie de "divisão do trabalho", na qual o Governo Federal centraliza muitas das atividades de planejamento e de formulação de políticas públicas, enquanto os governos municipais figuram apenas como implementadores de políticas públicas.

Simultaneamente, a partir da década de 1990, momento em que se passa a implantar de forma organizada a reforma do Estado no Brasil, há o deslocamento 
de um modelo de intervenção focado no Estado (Estadocêntrico), para outro, centrado na sociedade (sociocêntrico) (KEINERT, 2000).

É nesse contexto que surgem experiências envolvendo novos arranjos e relações entre Estado e sociedade civil em diferentes países da América Latina, dentre os quais o Brasil (OSZLAK, 1997). A Articulação do Semiárido é uma dessas iniciativas, e tem se mostrado uma das mais significativas e representativas. As lições mais interessantes oferecidas pelo caso da ASA remetem, justamente, ao fato da rede ter conseguido conquistar um espaço importante na agenda decisória, podendo intervir de forma bastante expressiva na política pública de acesso à água no SAB, por meio do P1MC e de seu programa-irmão, o P1+2 (Programa Uma Terra Duas Águas).

Desde seus primórdios, a partir dos primeiros projetos que desenvolveu, a ASA passou a sistematizar e articular as numerosas práticas tradicionalmente empregadas no Semiárido para mitigar os efeitos da seca. Conforme lembra Albuquerque (2010), os principais eixos orientadores das ações da ASA, que moldaram a forma que a rede acabou assumindo, envolvem a promoção da agricultura familiar de base agroecológica, o respeito às etnias, a valorização do conhecimento dos agricultores e agricultoras, a promoção das relações equitativas de gênero, a democratização do acesso à terra e à água, o combate à desertificação e a educação para a convivência com o semiárido. São linhas de ação que se complementam e se reforçam, estando, em conjunto, plenamente alinhadas com a proposta de criação de uma cultura de convivência com a seca, conforme anteriormente apontado.

Tal abordagem tem viabilizado condições de vida dignas para as famílias do Semiárido, que não mais necessitam abandonar o local onde vivem. As implicações da adoção dessa nova orientação são bastante claras: busca-se garantir a permanência das famílias na região em que vivem, fortalecendo a identidade local, preservando os costumes e tradições e intensificando o vínculo com a terra. Para além da garantia do acesso à água para consumo ou produção, viabilizado pela construção das cisternas, essa abordagem está baseada em ações de desenvolvimento local, de inclusão social e de empoderamento de atores historicamente marginalizados nos processos de tomada de decisão.

A partir do arranjo inicial que deu origem à ASA, coube às organizações que viriam a compor a rede conceber ações efetivas, que pudessem ser implementadas a partir da sociedade civil organizada e que, ao mesmo tempo, pudessem se vincular a políticas públicas no nível federal. A experiência da ASA configura, portanto, um caso que oferece elementos importantes para a concepção de um novo modelo de política pública que seja adequado para o estímulo ao desenvolvimento de tecnologias sociais.

A literatura produzida a partir dos países do hemisfério norte que tem se ocupado especificamente com a temática da produção de conhecimento e tecnologias para 
a inclusão social tem se referido a essa forma alternativa de formular, implementar e avaliar políticas públicas como "paradigma de políticas para a coesão social", ou SCoPP (Social Cohesion Policy Paradigm) (HAGENDIJK; HEALEY; PEREIRA, 2009).

Optamos aqui por usar os termos "modelo" ou "abordagem", e não "paradigma de política pública”, conforme apresenta Hall (1993), por entendermos que o processo de construção da agenda, de formulação, implementação e avaliação de políticas públicas não constitui uma categoria claramente delimitada. A política pública é o Estado e a sociedade em movimento. É o produto de tensões, conflitos e alianças dinâmicas, cujo curso é legitimado por argumentos muitas vezes efêmeros e voláteis. A ideia de paradigma, portanto, parece ser pouco aplicável para a compreensão dos processos associados às políticas públicas. Ademais, como lembra Kay (2005), a noção de paradigma pode servir para explicar situações estáticas, mas é pouco útil para compreender mudanças.

$\mathrm{Na}$ experiência aqui analisada, tais "mudanças", conforme apresentado acima, remetem a um novo arranjo de política pública, com participação ativa da sociedade civil organizada, e por meio do estímulo a tecnologias que, para além de atacar apenas um problema pontual (no caso, a falta de acesso regular à água), geram dinâmicas socialmente inclusivas, com o empoderamento das comunidades e com a valorização da cultura, dos valores e dos conhecimentos locais.

Como potencializar ações semelhantes, de modo a se constituir uma nova abordagem em políticas públicas que tenham como objetivo promover o desenvolvimento local pautado em tecnologias adequadas para tanto? Não há, evidentemente, um caminho único para alcançar esse objetivo. Contudo, a análise de experiências que seguem nessa direção - sejam elas casos de "sucesso" (caso do P1MC) ou de "fracasso" - oferece algumas pistas importantes para a concepção desse novo modelo de intervenção estatal.

É preciso garantir a participação das comunidades na elaboração das políticas públicas que pretendem catalisar dinâmicas locais de desenvolvimento. Esse processo tende a conduzir a ações mais aderentes ao contexto e, paralelamente, fortalecem a identidade local e geram processos de aprendizado junto aos atores que passam a ser incorporados no processo decisório. Aprender a participar é, evidentemente, um processo fundamental para a consolidação de práticas democráticas. É necessário romper as barreiras à participação construídas dentro do âmbito do Estado, como práticas herdadas dos tempos de autoritarismo.

Em última instância, construir "políticas públicas em escala humana" constitui um grande desafio, sobretudo para um Estado como o brasileiro, impregnado por uma cultura de valorização de grandes projetos e programas, em detrimento de uma forma de intervenção pautada pelas especificidades locais. Contudo, experiências como a que aqui descrevemos parecem mostrar que outro caminho é não apenas possível, mas também bastante promissor. 


\section{Considerações finais}

Tecnologias são frutos de processos políticos de constante negociação e compromisso entre os atores sociais. São definidas de acordo com o contexto de sua relação com a sociedade. Elas não podem ser removidas do seu contexto, e, portanto, não são neutras.

Conceber políticas públicas que tenham a tecnologia como elemento fundamental e que estejam orientadas ao desenvolvimento local representa um desafio ao Estado brasileiro, cuja trajetória tem sido pautada por uma cultura de intervenção pouco aderente ao contexto local.

Dessa maneira, a preocupação para com a temática do desenvolvimento local se aproxima do movimento pela Tecnologia Social, entendida como a base material e cognitiva de uma sociedade mais justa, solidária, democrática e ambientalmente sustentável, em consonância com os princípios da autogestão, do cooperativismo e do desenvolvimento local. Não obstante, verifica-se que, até o presente momento, tentativas de aproximar esses dois campos ainda são escassas.

Para que se possa conceber estratégias de desenvolvimento local, é imprescindível que se reconheça a importância da questão tecnológica. No caso aqui analisado, nota-se que a cisterna é o motor do P1MC. Contudo, o que ela garante às famílias que a recebem não é apenas água. É saúde, é dignidade, é esperança. A identidade local, valorizada pelas mudanças introduzidas pelas cisternas, torna-se, então um fator que acaba por potencializar o sucesso das intervenções. A cisterna, assim, representa uma tecnologia social que, para além do acesso à água, tem garantido a inclusão social, o empoderamento de atores politicamente marginalizados e a construção de laços de solidariedade e de cooperação nas comunidades.

Assim como a tecnologia das cisternas foi reaplicada pelo SAB, seria muito positivo observar também o transbordamento da abordagem de política pública por trás do Programa Um Milhão de Cisternas para outras ações orientadas para a intervenção sobre problemas locais. Para tanto, porém, é necessário aproximar as reflexões e ações sobre Tecnologia Social e sobre Desenvolvimento Local. Assim, acreditamos ser possível conformar políticas e tecnologias que valorizem os valores, as práticas e os conhecimentos das comunidades locais.

\section{Referências}

ALBUQUERQUE, M. C. Novos paradigmas no Semi-Árido Brasileiro: a experiência da ASA na construção de novas modalidades de políticas públicas. In: MORAIS, L.; BORGES, A. (Org.). Novos paradigmas de produção e consumo: experiências inovadoras. São Paulo: Instituto POLIS, 2010. 
CLARKE, R. The science of war and peace. Nova York: McGraw Hill, 1972.

DAGNINO, R. P. A tecnologia social e seus desafios. In: Tecnologia social: uma estratégia para o desenvolvimento. Rio de Janeiro: Fundação Banco do Brasil, 2004.

DAGNINO, R. P.; BRANDÃO, F. C.; NOVAES, H. T. Sobre o marco analíticoconceitual da Tecnologia Social. In: Tecnologia Social: uma estratégia para o desenvolvimento. Rio de Janeiro: Fundação Banco do Brasil, 2004.

DINAR, A. The political economy of water pricing reforms. Oxford, Reino Unido: Oxford University Press, 2000.

GNADLINGER, J. Captação de água de chuva para o desenvolvimento sustentável do semi-árido brasileiro: uma abordagem focalizando o povo. In: $3^{\circ}$ Simpósio Brasileiro de Captação de Água de Chuva no Semi-Árido. Campina Grande, PB. 2001.

GUIMARÃES FILHO, C.; LOPES, P. R. C. Elementos a serem considerados na Formulação de um Programa de Convivência com a Seca para o SemiÁrido Brasileiro. Petrolina (PE): EMBRAPA Semi-Árido, 2002.

HAGENDIJK, R.; HEALEY, P.; PEREIRA, T. Researching inequality through science and technology. Oxford, Reino Unido: James Martin Institute, 2009.

HALL, P. A. Policy paradigms, social learning and the State: the case of economic policymaking in Britain. Comparative Politics, v. 25, n. 3, 1993.

KAY, A. A critique of the use of path dependency in Policy Studies. Public Administration, v. 83, n. 3, 2005.

KEINERT, T. M. M. Administração pública no Brasil: crises e mudanças de paradigmas. São Paulo: FAPESP, 2000.

LIPPS, A. Statistics. In: SMITHSONIAN INSTITUTION (Ed.). Design for the other 90\%. Nova York: Smithsonian Institution, 2007.

OSZLAK, O. Estado y sociedad: nuevas reglas de juego? Revista Reforma y Democracia, n. 9, 1997.

SCHUMACHER, E. F. Small is beautiful: economics as if people mattered. Point Roberts: Hartley \& Marks, 1999. Original de 1974. 
VARSAVSKY, O. Por uma política científica nacional. Rio de Janeiro: Paz e Terra, 1976.

Endereços para correspondência:

Rafael de Brito Dias - rafaeldias@ige.unicamp.br Rua João Pandiá Calógeras, 51, Cidade Universitária 13083-870 Campinas/SP, Brasil 